\title{
PRE-SERVICE TEACHERS' PREPAREDNESS AND CONFIDENCE IN TEACHING LIFE SCIENCES TOPICS: WHAT DO THEY LACK?
}

\author{
Lydia Mavuru, \& Oniccah Koketso Pila \\ Department of Science and Technology Education, University of Johannesburg (South Africa)
}

\begin{abstract}
Pre-service teachers' preparedness and confidence levels to teach is a topical subject in higher education. Previous studies have commented on the role of teacher in-service training in preparing teachers for provision of meaningful classroom experiences to their learners, but many researchers regard pre-service teacher development as the cornerstone. Whilst teacher competence can be measured in terms of different variables e.g. pedagogy, knowledge of the curriculum, technological knowledge etc., the present study focused on teacher competency in terms of Life Sciences subject matter knowledge (SMK). The study was framed by pedagogical content knowledge (PCK). The study sought to answer the research question: How do preservice teachers perceive their levels of preparedness and confidence in teaching high school Life Sciences topics at the end of their four years of professional development? In a qualitative study, a total of 77 pre-service teachers enrolled for the Methodology and Practicum Life Sciences course at a university in South Africa participated in the study. Each participant was tasked to identify topic(s)/concept(s) in Life Sciences they felt challenged to teach, provide a critical analysis of the reasons for that and map the way forward to overcome the challenges. This task was meant to provide the pre-service teachers with an opportunity to reflect and at the same time evaluate the goals of the learning programme they had gone through. Pre-service teachers' perspectives show their attitudes, values and beliefs based on their personal experiences which therefore help them to interpret their teaching practices. The qualitative data was analysed using content analysis. The findings showed that whilst pre-service teachers were competent to teach other topics, the majority felt that they were not fully prepared and hence lacked confidence to teach the history of life on earth and plant and animal tissues in grade 10; excretion in animals particularly the functions of the nephron in grade 11; and evolution and genetics in grade 12. Different reasons were proffered for the lack of preparedness to teach these topics. The participants regarded some of these topics as difficult and complex e.g. genetics. Evolution was considered to be antagonistic to the participants' and learners' cultural and religious belief systems. Hence the participants had negative attitudes towards them. Some of the pre-service teachers indicated that they lacked interest in some of the topics particularly the history of life on earth which they considered to be more aligned to Geography, a subject they did not like. As remedies for their shortcomings in the content, the pre-service teachers planned to co-teach these topics with colleagues, and others planned to enrol for content enrichment programmes. These findings have implications for teacher professional development programmes.
\end{abstract}

Keywords: Teacher confidence, Life Sciences, preparedness, pre-service teachers.

\section{Introduction}

For meaningful teaching to occur in the classrooms, teachers need to be fully prepared and be confident to teach the subject matter. In as much as previous studies have commented on the role of teacher in-service training and experience in preparing teachers for provision of meaningful classroom experiences to their learners (e.g. Harris \& Saas, 2011), many researchers regard pre-service teacher development as the cornerstone (e.g. Yildirim \& Kalman, 2017). Teachers are required to possess different knowledge domains such as contextual knowledge, curriculum knowledge, knowledge of the learners, pedagogical content knowledge and the subject matter knowledge. It is imperative for teachers to exhibit these differentiated yet integrated knowledge domains to effectively guide the learning process (Botha \& Reddy, 2011). Teacher education programmes should equip the pre-service teachers with these knowledge domains as this helps pre-service teachers to shape their teaching approaches and in developing their teacher identity. Chang-kredl and Kingsley (2014) identified confidence to teach as one of the crucial elements of pre-service teachers' self-identity.

A study by Cimer (2012) confirmed the difficulties associated with the teaching and learning of some of the biological concepts. A point to note is that many pre-service teachers experienced some challenges when learning some of the Life Sciences concepts during their high school years, thus these challenges have also persisted throughout their professional development journey. Thus said, Chang-kredl and Kingsley (2014) acknowledged prior experiences as another aspect which forms teacher identity. 
Inadequate mastery of the subject content negatively affects the pre-service teachers' teaching (Botha \& Reddy, 2011), therefore, the current study sought to establish the pre-service teachers' confidence and preparedness to teach Life Sciences towards the end of their teacher education programme. The rationale for this study comes from the argument that the teaching of content to pre-service teachers should not be done in isolation to the teaching of representations to be used and the teaching strategies if teacher preparation is to be successful. The context of the teacher development programme that these pre-service teachers were enrolled in was split between two faculties where the subject matter was taught in the Faculty of Science and the education courses were taught in the Faculty of Education. The present study sought to answer the research question: How do pre-service teachers perceive their levels of preparedness and confidence in teaching high school Life Sciences topics at the end of their four years of professional development? An honest reflection of one's abilities is crucial in self-development (Kayapinar, 2016) as it helps one to gain self-efficacy.

\section{Literature review}

Previous research has shown that Life Sciences topics such as protein synthesis, transport in plants, genetics, mitosis and meiosis, hormonal regulation, gaseous exchange, respiration, are considered to be complex (Cimer, 2012). Cimer (2012) attributes this complexity to the abstract nature of science, the overloaded biology curricular, and the difficulty in the concepts and processes. It is unfortunate that due to these identified challenges Life Sciences learning is sometimes based on the memorisation of concepts rather than understanding of the content. The teaching approaches teachers employ tend to contribute to learners' inability to understand the content (Cimer, 2004). There is a need for teachers to be well equipped with the subject matter knowledge, skills, values, principles, teaching and learning approaches and how such approaches can be implemented in a Life Sciences classroom. Teacher education programmes are called to develop pre-service teachers with the relevant knowledge and skills to teach their learners meaningfully. Whilst pre-service teachers are considered to be at their infant stage of the teaching profession, considerable effort to develop them fully for their role in the classrooms is imperative. It was however found that pre-service teachers battle to apply the knowledge which they have learned during teacher development programmes due to the lack of knowledge regarding the realities in schools (Coetzee (2012). As a result pre-service teachers lack confidence and are not well prepared to teach some of the Life sciences topics.

At the end of their teacher development programme, pre-service teachers are expected to be well grounded with the necessary knowledge and skills to teach and manage the diverse classroom contexts. Thus, if they indicate elements of incompetence it means they are not well developed, and as such they become less confident to teach when they become qualified teachers (Botha \& Reddy, 2011). Teachers' lack of confidence and preparedness to teach the subject they are trained in raises concerns on how that could impact negatively on the performance of the learners. In a study conducted by Setlalentoa (2018) learners expressed the difficulties they experienced in understanding the Life sciences concepts such as genetics and inheritance, meiosis and mitosis, emphasising the many vocabularies that accompany the subject matter and the limited time which they have to learn the content. The learners became disinterested to continue studying the subject citing the teachers' lack of subject matter knowledge and pedagogical content knowledge as some of the factors causing the challenges learners were facing (Setlalentoa, 2018).

The manner in which Life Sciences content is taught contributes to learners' failure to realise the value and meaning of the concepts taught. To this, Cimer (2004) bemoaned that in most cases, Biology teaching is teacher-centred which demotivates learners from attentively listening and engaging during the teaching and learning process. Lack of resources is also perceived as a factor which forces the teachers to engage in the teacher-centred approach (Cimer, 2012). Pre-service teachers are not well equipped with ideas of how to approach certain Life Sciences topics in a context with no relevant teaching resources, and this affects their competency in teaching the particular subject matter. Language of learning and teaching has also been found to be a factor which impedes learners and teachers alike to understand and explain science terminologies and processes (Mavuru \& Ramnarain, 2020). Considering the many Latin and Greek words which are embedded in the Life Sciences terminology and processes, learners and pre-service teachers alike, find these terms challenging.

In an attempt to expose pre-service teachers to the realities of the school and classroom contexts, the teacher education programmes allocate time which pre-service teachers spend in schools teaching (Dias-Lacy \& Guirguis, 2017). This provides an opportunity for the pre-service teachers to interpret and articulate the school curriculum and utilise the knowledge and skills they learn in university and as such, they get to realise their capabilities and shortcomings.

\section{Conceptual framework}

This study is underpinned by Pedagogical Content Knowledge (PCK) as the conceptual framework as proposed by Shulman (1986). PCK is a special type of knowledge which amalgamates the 
content knowledge and the pedagogical knowledge. In essence, PCK is an essential aspect of teaching and learning and holds the potential to stimulate an effective learning environment. Whilst Shulman stipulates that teachers should not only be knowledgeable about the subject matter but also strategies to teach the content to the learners, the present study focuses on the teacher development of subject matter knowledge, a domain within PCK. The importance of subject matter knowledge in PCK was demonstrated in a study by Rollnick et al. (2008) where a teacher was found to display powerful PCK due to his nuanced subject matter knowledge.

\section{Research methodology}

This study followed a qualitative research design using a case study approach (Merriam, 2009). Qualitative research seeks to establish the manner in which individuals interpret their experiences (Merriam, 2009). This approach allowed for an in-depth establishment of the pre-service teachers' preparedness and confidence to teach particular Life Sciences topics.

\subsection{Selection of the participants}

77 pre-service teachers enrolled for a Life Sciences methodology and practicum course at a South African University were purposively selected to participate in the study. These pre-service Life Sciences teachers were in their final year of a four year teacher development programme. The nature of the teacher development they went through was that they learned the Life Sciences subject matter in the Faculty of Science during the first three years. All the education courses were offered in the Faculty of Education. The pre-service teachers were also involved in the actual classroom teaching of Life Sciences (work integrated learning) at different schools throughout their teacher development.

\subsection{Data collection and analysis}

To collect data, each pre-service Life Sciences teacher was tasked to do the following: 1. To identify a topic/concept in Life Sciences they were not confident to teach; 2 . To critically present reasons for such a discomfort and map the way forward on how they could develop the knowledge and skills to teach it. The task allowed pre-service teachers to intensively engage with the Life sciences content and reflect on their experiences during classroom practice. Each pre-service teacher then submitted a report. Data was analysed using content analysis (Marshall \& Firth, 2017) wherein codes and categories were identified leading to relational analysis.

\section{Findings}

The findings showed that whilst pre-service teachers were competent to teach other topics, the majority felt that they were not fully prepared and hence lacked confidence to teach some topics. Most of these pre-service teachers articulated their lack of confidence in teaching topics such as history of life on earth and plants and animal tissues in grade 10; excretion in grade 11; and evolution and genetics in grade 12. The pre-service teachers' reasons for their lack of confidence and preparedness to teach these topics were attributed to factors related to the complexity and difficulty of the subject matter, and attitudes towards the topics.

Some of the pre-service teachers indicated that they lacked interest in some of the topics particularly the history of life on earth which they considered to be more aligned to Geography, a subject they did not like. Because of such negative attitudes, the participants failed to engage with this content meaningfully and did not give it the attention it deserved. Thus said, the pre-service teachers' capabilities to teach this topic was compromised. This has implications on the learning experiences grade 10 learners will have considering that the CAPS document stipulates that the topic requires a total of 6 weeks of teaching which translates to 24 hours of engagement, to show the importance placed on the topic. The following is one of the pre-service teacher's comment regarding this topic:

Participant 1: The main reason I am not confident to teach the topic of history of life on earth is that I fail to have perspective into the millions of years ago.

Considering the participant's sentiments, it shows that such teacher feelings or attitudes towards the topic will prevent the teacher from even enriching one's content knowledge and let alone acquire necessary skills to teach the topic meaningfully to the learners.

In the case of the topic evolution, the pre-service teachers considered it to be antagonistic to their cultural and religious belief systems and those of the learners. They indicated that when teaching this topic particularly the evolution of humankind, it felt as if they would be challenging the belief systems which learners have been taught to believe in from an early age and continue upholding such beliefs in their homes. They considered the topic as having a lot of controversy which makes is sensitive to some learners. One participant indicated, "I am very uncomfortable hence not prepared and confident to teach this topic because I fear that learners along with their parents might think I am challenging their faith"

The pre-service teachers attributed their lack of confidence to teach topics such as genetics and excretion to the abstract nature and complexity of the concepts. These participants also mentioned that 
there are specialised terminologies used in these topics, which make it difficult for one to understand them. As such, those pre-service teachers indicated that they also found it difficult to explain the concepts and processes involved considering that they themselves lack the required level of subject matter knowledge.

In addition to some of the personal reasons pre-service teachers mentioned with regards to their lack of preparedness and confidence to teach some topics, they identified profound contextual factors which limited their horizons to teach the topics. Firstly, some of the participants placed the blame on their high school Life Sciences teachers and their university lecturers who failed to demonstrate adequate knowledge and skills when teaching them some of the topics. This is encapsulated in one of the participants' report.

Participant 2: Regarding the topic tissues, I am not one hundred percent confident to teach and it stems from my time as a learner in high school. My teacher was boring as she would just sit by her desk and read information in the textbook.

This shows that a vicious cycle of incompetency has been created, which will have a ripple effect at so many levels if not addressed. In this kind of reflection, some of the pre-service teachers deeply reflected on the situation they found themselves in which in a way helped them to take responsibility of their predicament. An example is one of the participants who pointed out that whilst he could trace the root of his lack of preparedness to teach some topics to his high school teacher, he however realised that he could have taken responsibility and made an effort to self-study and do more research since he was not satisfied with the experiences in the classroom. Some of the general reasons given by the pre-service teachers for their failure and discomfort in teaching particular topics was drawn from the lack of adequate resources. An example was given by one of the participants who reported the following:

Participant 3: There are concepts which make it difficult for one to teach without resources, particularly the abstract concepts.

Specific to this problem, these pre-service teachers were referring to both plant and animal tissues which made it difficult for them to explain the concepts meaningfully to the learners without using microscopes. These pre-service teachers had had an experience of teaching such concepts during work integrated learning in schools hence they indicated how difficult it was to accommodate learners who preferred seeing and touching. Some of the pre-service teachers elaborated on the issue of resource unavailability where their teachers did not use videos, slides, other than simply reading from the textbook and expected them as learners to discern the important knowledge and skills to be mastered.

In their reports the pre-service teachers made an undertaking by mapping the way forward on how they could develop the knowledge and skills to teach the topics they found themselves not confident and less prepared to teach. Most of these pre-service teachers indicated their willingness to initiate collaborative teaching with fellow teachers in a process referred to as team teaching. Their justifications were that if one is strong in teaching certain concepts, the individual should be able to teach the other colleagues' classes. Through this way, no learner would be disadvantaged because of the teachers' lack of competency. Collaboration with fellow teacher remains one of the crucial elements of teacher development, especially engaging with experienced in-service teachers considering that the developmental process occurs when the mentor is more knowledgeable than the other, hence mentorship between in-service and pre-service teachers is recommended.

Some of the pre-service teachers indicated that they were willing to enrol in content enrichment programmes specific for the topics they struggled in. They indicated that they would utilise technology to enrich their knowledge. Some of the pre-service teachers also pointed out that navigating through technology would assist them to obtain resources, encourage them to become innovative in their teaching, a skill needed in the $4^{\text {th }}$ industrial revolution.

\section{Discussions}

Pre-service teachers identified different topics which they were not confident to teach which were influenced by factors such as lack of content knowledge, contradiction with one's beliefs and religion, former high school teacher's approach when teaching the topic, and lack of interest in the topic. As a result of these factors, pre-service teachers struggled to apply robust teaching approaches when teaching those topics. Considering the difficulties mentioned by the pre-service teachers, it shows that they did not only impact on their subject matter knowledge but also on their pedagogical knowledge to teach the topics. Thus said, teachers' topic specific PCK is underdeveloped. This is so because an early study by Rollnnick et al. (2008) identified the role of subject matter knowledge in the teachers' PCK and that the lack of subject matter knowledge is problematic and is an issue of concern in South Africa.

Being well knowledgeable and passionate about the subject matter raises the potential of the teacher to implement innovative strategies to support learners' learning. The topic evolution has proved to be challenging to both teachers' and learners' religious beliefs, thus the pre-service teachers indicated their discomfort and lack of confidence thereof to teach such a controversial topic particularly human evolution. This therefore influences in a negative way the manner in which teachers would teach such concepts to their learners because Mavuru and Ramnarain (2020) found that the learners' socio-cultural 
backgrounds which includes their belief systems influences how they learn or engage with the concepts taught. Notably, it was also found that ignoring learners' worldviews in the teaching and learning process, impacts negatively on learners' conceptual understanding (Mavuru \& Ramnarain, 2020).

\section{Conclusions}

The study focused on answering the research question: How do pre-service teachers perceive their level of preparedness and confidence in teaching high school Life Sciences topics at the end of their four years of teacher professional development? Pre-service Life Sciences teachers were not entirely confident and prepared to teach particular topics. One major identified factor is the lack of the subject matter knowledge which had an effect on the pre-service teachers' PCK. The participants indicated that some of the Life Sciences content is complicated and complex not only to the learners but also to the teachers. The topics identified by the pre-service teachers identified which they felt not prepared and not confident to teach ranged from grade 10 to grade 12 which included the history of life on earth; and plants and animal tissues in grade 10; excretion in grade 11; and evolution and genetics in grade 12. The teachers proffered various reasons for their lack of preparedness which included the poor learning experiences in high school; and the poor university preparation in the content area. The findings have implications on the teacher professional development and informs the future studies which may focus on the initiatives of the teacher education developmental programmes to assist pre-service teachers.

\section{References}

Agbo, S.A. (2003). A learning community model for professional development and transformational teacher education. In: Preston DS (ed.). The Idea of Education. Amsterdam, NY:Radopi.

Botha, M.L \& Reddy, C.P.S. (2011). In-service teachers' perspectives of pre-service teachers' knowledge domains in science. South African Journal of Education, 31, 257-274.

Chang-kredl, S. \& Kingsley, S. (2014). Identity expectations in early childhood teacher education: Pre-service teachers' memories of prior experiences and reasons for entry into the profession. Teaching and Teacher Education, 43, 27-36.

Cimer, A. (2004). A study of Turkish biology teachers' and student's views of effective teaching in schools and teacher education. EdD Dissertation. The University of Nottingham, Nottingham: UK.

Cimer, A. (2012). What makes biology learning difficult and effective: Students' views. Education Research and Reviews, 7(3), 61-71.

Coetzee, A. (2012). Presentation: NSC to CAPS by the Gauteng Department of Education. Paper presented in seminar on NCS to CAPS. Kgorong Hall: UNISA.

Dias-lacy, S.L, \& Guirguis, R.V. (2017). Challenges for new teachers and ways of coping with them. Journal of Education and Learning, 6(3), 265-271.

Harris, D.N. \& Sass, T.R. (2011). Teacher training, teacher quality and student achievement. Journal of Public Economics, 95(7-8), 798-812. https://doi.org/10.1016/j.jpubeco.2010.11.009

Kayapinar, U. (2016). A study on reflection in in-service teacher development: Introducing reflective practitioner development model. Educational Sciences: Theory \& Practice, 16(5), 1671-1691. https://doi.org/10.12738/estp.2016.5.0077

Marshall, M. \& Firth, S. (2017). My revision notes: AQA A level psychology. London: Hodder Education.

Mavuru, L. \& Ramnarain, U. (2020). Language affordances and pedagogical challenges in multilingual grade 9 Natural Sciences classrooms in South Africa. International Journal of Science Education, 42(14), 2472-2492. https://doi.org/10.1080/09500693.2019.1655177

Mavuru, L., Ramnarain, U. (2020). Learners' socio-cultural backgrounds and science teaching and learning: a case study of township schools in South Africa. Cultural Studies of Science Education, 15(4), 1067-1095. https://doi.org/10.1007/s11422-020-09974-8

Merriam, S.B. (2009). Qualitative research: A guide to design and implementation ( $2^{\text {nd }}$ ed). San Francisco, CA: Jossey-Bass.

Rollnick, M., Bennett, J., Rhemtula, M., Dharsey, N., \& Ndlovu, T. (2008). The place of subject matter knowledge in pedagogical content knowledge: A case study of South African teacher. International Journal of Science Education, 30 (10),1365-1387. https://doi.org/ $10.1080 / 09500690802187025$

Setlalentoa, W. (2018). Experiences of pre-service teachers on Life Sciences topics and learning. What makes learning difficult and effective? 40th International Academic Conference, 219-229

Shulman, L. (1986). Those who understands: Knowledge growth in teaching. Educational Researcher, 15 (2), 4-14.

Yildirim, I \& Kalman, M. (2017). The validity and reliability study of the Turkish version of the preparedness to teach scale. Kastamonu Education Journal, 25 (6), 2311-2326. 